\title{
A Comprehensive Tool to Measure Enterprise e-Business Performance in Global Management Environment
}

\author{
Chui Young Yoon
}

\begin{abstract}
Enterprises have used e-business systems to efficiently perform their business in a global management environment. Firms have applied their e-business capabilities to management activities in order to raise the performance of business execution and improve their competitiveness in a global market environment. In this business environment, the measurement and management for the performance of a firm's e-business execution need to efficiently build its e-business environment and effectively improve its e-business capability and management results. We present a comprehensive tool for measuring an enterprise e-business performance to totally manage and improve the e-business performance in this environment. The measurement factors and items for a firm e-business performance are developed and extracted from the definition and major components of a general firm performance in previous literature. The generated measurement items were verified by factor analysis and reliability analysis through a pilot test. The twelve items were developed from twenty items by these analyses. This study developed a 11-item tool that can totally analyze an enterprise e-business performance in a global management environment. The developed tool consists of four analysis factors and twelve items.
\end{abstract}

Index Terms - e-Business, e-business performance, enterprise performance, analysis tool.

\section{INTRODUCTION}

The needs for effective operation of firm resources have been raised because of the intense competition facing in each firm. With developing of information technology, most firms have implemented their e-business capabilities to efficiently perform management activities and improve the performance of business tasks in an e-business management environment [1], [2]. Enterprises have applied their e-business capabilities to management activities in order to efficiently raise the performance of business execution in a global management environment. In this business environment, the measurement for the performance of an enterprise's e-business execution needs to efficiently build and improve the e-business environment appropriate for its management strategy and activities, and its business departments. Enterprise e-business performance means the business results that a firm performs its management and business activities based on its e-business capability in an e-business perspective. But a comprehensive and practical tool to measure an enterprise e-business

Manuscript received October 3, 2015; revised December 17, 2015. This research was supported by Basic Science Research Program through the National Research Foundation of Korea (NRF) funded by the Ministry of Education, Science and Technology (NO: 2013R1A1A2012350).

C. Y. Yoon is with the Korea National University of Transportation, Cheongju, 320-801 South Korea (e-mail: yoon0109@ut.ac.kr). performance has rarely been studied in previous studies. That is, we need a comprehensive and objective instrument that can effectively measure an enterprise e-business performance in terms of its entire e-business performance.

Therefore, this study provides a comprehensive and structural tool that can efficiently measure an enterprise e-business performance for effectively building its e-business capability and improving its e-business performance, and for systematically establishing and improving its e-business environment in terms of an entire e-business performance.

\section{PRevious Studies}

E-business has realized as a core paradigm of firm management, many studies defined it variously, depending on their viewpoints [1]-[3]. By researching previous studies, this research defined that e-business is an approach to increase the competitiveness of organizations by improving management activities through using IT and the Internet [1]-[3]. In this e-business environment, the measurement of a firm e-business performance is an important procedure to effectively raise the e-business performance and enterprise competitiveness in a global management environment.

The previous literature presents the enterprise performance in a variety of perspectives [4]-[16]. The measurement variables of firm performance are operational performance (inventory turnover and accounts receivable turnover), growth performance (sale revenue growth), and profitability performance (sales gross and profit margin) [5]. Enterprise performance includes process performance and outcome performance. Process performance reflects the performance of business operation process, like cost, products or service level and so on [6]. Outcome performance reflects the performance of business outcome, like property returns ratio, market sharing and so on. These studies focused on financial and non-financial perspectives. In financial research, the measurement of firm performance was studied in terms of sale growth, earning growth, market share, return on assets (ROA), return on sales (ROS), and market value [11], [12]. The firm performance includes three factors such as improving client satisfaction, enhancing organizational competitiveness, and enhancing organizational image [14]. In non-financial research, an enterprise's performance was measured by efficiency, effectiveness, profitability, quality of service, client satisfaction, and productivity [15]. Their satisfaction level about their firm's performance is presented in terms of growth in sale, growth in profits, and growth in market share [16]. By exploring these studies, this research describes an enterprise e-business performance as the effectiveness and efficiency of its management activities that 
are improved by applying enterprise e-business capability to its management activities. And, enterprise e-business performance is able to transform enterprise performance into a type of enterprise performance based on an e-business performance perspective.

Hence, enterprise e-business performance (EEBP) can be defined as the performance that an enterprise can obtain with applying the e-business capability to its management activities and business tasks in an e-business management environment. EEBP means a total e-business performance that an enterprise can get from applying its e-business capability to its management activities and business tasks in a global management environment.

Based on these previous studies, this research extracts the measurement factors and items to gauge an enterprise e-business performance in an e-business perspective as follows: e-business operation performance (efficiency of business process, inventory turnover and accounts, quality of services, and client satisfaction), e-business growth performance (sale revenue growth, market growth, market value, and return on sale), e-business profitability performance (sale gross and profit margin, net income growth, growth in profits, and cash turnover ratio), and e-business competitiveness performance (sale growth rate, capital structure, market share, number of patents, customer share, and R\&D expenditure ratio) [6]-[16]. We use these items as measurement items with which to gauge the EEBP through the verification process of a validity and reliability analysis.

\section{METHODS}

This research initially generated 21 measurement items for EEBP based on definitions and components of enterprise performance [6]-[16]. We analyzed the construct validity of the developed items to ensure that EEBP is efficiently measured by the items. The construct validity of the model was researched by many researchers. These studies presented two methods of model construct validation: (1) correlations between total scores and item scores, and (2) factor analysis [17]-[19]. Etezadi-Amoli \& Farhoodmand (1996) and Tippins et al. (2003) used factor analysis to verify the validity of the measurement tool construct [17], [18]. Torkzadeh \& Lee (2003) used correlation analysis to verify the validity of the measurement tool construct [19]. This research is likely to verify the validity of the measurement tool construct and the extraction of adequate measurement items by factor analysis and reliability analysis. The ratio of sample size to number of measurement items (11:1) was above the minimum (10:1) ratio suggested for factor analysis [18], [19]. The analysis questionnaire used a five-point Likert-type scale; where, 1: not at all; 2: a little; 3: moderate; 4: good; 5: very good. The survey was gathered data from a variety of industries, business departments, experience, and education. We performed two kinds of survey methods: direct collection and e-mail. The respondents either directly mailed back the completed questionnaires or research assistants collected them 2-3 weeks later. The collected questionnaires represented 38 percent of the respondents.

\section{A. Sample Characteristics}

This research collected a sample of 168 usable responses collected from a variety of industries and business departments. This excluded six incomplete or ambiguous questionnaires, leaving 162 usable questionnaires for statistical analysis. All respondents had college or university degrees in: humanities and societies (17.3\%), management and economics $(29.6 \%)$, engineering $(34.0 \%)$, and science $(19.1 \%)$. The respondents in terms of business departments were identified as strategy planning (16.0\%), development and maintenance $(14.6 \%)$, business application $(41.0 \%)$, and administration support $(28.4 \%)$. The respondents identified themselves as top manager (4.9\%), middle manager $(39.5 \%)$, and worker $(55.6 \%)$. The respondent had on average of 7.8 years of experience (S.D. $=1.019$ ) in their field, their average age was 34.8 years old (S.D. $=5.012$ ), and their gender, male $(69.1 \%)$ and female $(30.9 \%)$

\section{B. Analysis and Discussion}

With factor analysis and reliability analysis, the first 21 measurement items were reduced to 11 items, with 10 items were deleted, with applying the criterion of previous studies [17]-[19]. The elimination was sufficiently considered to ensure that the retained items were adequate measurement items of EEBP. The validity and reliability of the developed tool were also verified through factor analysis and reliability analysis. They were used to identify the underlying factors or components that comprise the EEBP construct. Each of the 11 items had a factor loading $>0.634$. The reliability coefficients (Cronbach's alpha) of four potential factors had values > 0.802 as indicated in Table I, above the threshold recommended for exploratory research [17]-[19]. This research calculated the corrected item-total correlations between each variable and its corresponding factor in order to investigating the reliability and validity of the analysis items. These correlations along with alpha coefficients of each factor are presented in Table I. It also shows the alpha coefficients for the measurement factors if a measurement item was deleted from the scale. These coefficients indicate the relative contribution of a measurement item to the construction of a scale for measuring a particular factor. They are all in the acceptable range. Most corrected item-total correlations were greater than 0.601 , showing that the measurement items are good indicators of their corresponding factors. The extracted items have a validity and reliability in terms of a measurement construct based on the analysis results as presented in Table I.

And. construct validity is used to examine how well the results obtained from using the measure fit with the theories that lie behind the design of the instrument. There are two common forms of construct validity, convergent and discriminant validity [17]-[19]. This research uses two methods to confirm the construct validity of the EEBP: (1) the correlation matrix approach to investigate construct validity of the developed tool [19]; (2) correlation coefficients between each dimension of EEBP tool and average score of the EEBP tool. In the correlation matrix methods, this research examines convergent validity by determining whether relationships between scales of the same factor are higher than zero and large enough to execute discriminant validity analysis [20]. As shown in Table II, the lowest 
within-factor correlations of each factor (black and bold values) are as follows: e-business operation performance $(\mathrm{V} 01,03,04)=0.44$; e-business growth performance $(\mathrm{V} 06$, $08,10)=0.49$; e-business profitability performance $(\mathrm{V} 13,15$, $17)=0.45 ;$ and e-business competitiveness performance $(\mathrm{V} 19$, $21)=0.52$. These values are significantly higher than zero and thus they are large enough to carry out discriminant validity. This research also examines discriminant validity by counting the number of times that an item had a higher correlation with items of other factors than with those of its own factor [20]. In order to apply this criterion, Campbell and Fiske (1959) suggested that this number should be less than $50 \%$ of potential comparisons [21]. The correlation matrix shows only five violations for 404 potential comparisons.

TABLE I: RELIABILITY, VALIDITY, AND FACTOR LOADINGS OF EEBP CONSTRUCT

\begin{tabular}{|c|c|c|c|c|c|c|}
\hline \multirow{2}{*}{ Variable } & \multicolumn{4}{|c|}{ Factor Loading } & \multirow{2}{*}{$\begin{array}{l}\text { Corrected } \\
\text { Item-Total } \\
\text { Correlation }\end{array}$} & \multirow{2}{*}{$\begin{array}{c}\text { Coefficients } \\
\text { Alpha }\end{array}$} \\
\hline & Factor 1 & Factor 2 & Factor 3 & Factor 4 & & \\
\hline V01 & 0.763 & & & & 0.678 & \\
\hline V03 & 0.796 & & & & 0.712 & 0.812 \\
\hline V04 & 0.654 & & & & 0.657 & \\
\hline V06 & & 0.802 & & & 0.736 & \\
\hline V08 & & 0.826 & & & 0.638 & 0.842 \\
\hline V10 & & 0.724 & & & 0.691 & \\
\hline V13 & & & 0.811 & & 0.756 & \\
\hline V15 & & & 0.879 & & 0.641 & 0.849 \\
\hline V17 & & & 0.702 & & 0.612 & \\
\hline V19 & & & & 0.796 & 0.659 & ○० \\
\hline V21 & & & & 0.634 & 0.601 & 0.002 \\
\hline
\end{tabular}

TABLE II: CORRELATION MATRIX OF EEBP MEASURES

\begin{tabular}{llllllllllllll}
\hline V01 & & & & & & & & & & \\
V03 & $\mathbf{0 . 4 7}$ & & & & & & & & & \\
V04 & $\mathbf{0 . 5 2}$ & $\mathbf{0 . 4 4}$ & & & & & & & & \\
V06 & 0.33 & 0.24 & 0.46 & & & & & & & \\
V08 & 0.32 & 0.37 & 0.31 & $\mathbf{0 . 4 9}$ & & & & & & \\
V10 & 0.31 & 0.29 & 0.28 & $\mathbf{0 . 5 3}$ & $\mathbf{0 . 5 4}$ & & & & & \\
V13 & 0.28 & 0.31 & 0.34 & 0.33 & 0.28 & 0.31 & & & & \\
V15 & 0.24 & 0.28 & 0.30 & 0.29 & 0.27 & 0.33 & $\mathbf{0 . 4 8}$ & & & \\
V17 & 0.32 & 0.28 & 0.31 & 0.39 & 0.29 & 0.32 & $\mathbf{0 . 4 5}$ & $\mathbf{0 . 5 9}$ & & \\
V19 & 0.33 & 0.31 & 0.37 & 0.31 & 0.33 & 0.27 & 0.26 & 0.25 & 0.31 & \\
V21 & 0.36 & 0.27 & 0.31 & 0.24 & 0.29 & 0.30 & 0.34 & 0.27 & 0.37 & $\mathbf{0 . 5 2}$ & \\
& & & & & & & & & & \\
& V01 & V03 & V04 & V06 & V08 & V10 & V13 & V15 & V17 & V19 & V21
\end{tabular}

However, our efforts to provide additional evidence of this tool's validity, internal consistency, and stability are encouraged. This may be successfully achieved by accumulating many research findings and case studies.

\section{MEASUREMENT TOOL}

We presented the 11 measurement items appropriate for gauging EEBP. This research classified four factor groups from the factor analysis. The factor groups indicate the potential factors as major measurement components to gauge
EEBP. By investigating the analysis items of each factor group, this research identified the following four potential factors: factor 1: e-business operation performance; factor 2: e-business growth performance; factor 3: e-business profitability performance; and factor 4: e-business competitiveness performance. The potential 4 measurement factors are used as the 4 core measurement factors of our measurement tool construct. The meanings and measurement items of each factor are as follows. E-business operation performance presents the efficiency and effectiveness improved by applying the enterprise e-business capability to its management activities in enterprise e-business operation perspective. That is, the e-business operation performance indicates the result that a firm obtains from its e-business management activities in terms of e-business execution. It comprises efficiency of business process, quality of service, and client satisfaction in firm management activities. E-business growth performance indicates the efficiency and effectiveness raised by applying the enterprise e-business capability to its management activities in a firm growth perspective. It comprises sale revenue growth, return growth on sale, and market growth in an e-business perspective. E-business profitability performance means the efficiency and effectiveness improved by applying the firm e-business capability to its management activities in a firm profit perspective. It has sale gross and profit margin, growth in profits, and net income growth in an e-business perspective. E-business competitiveness performance refers to the efficiency and effectiveness increasing by utilizing the firm e-business capability for its management activities in an enterprise competitiveness perspective. Namely, e-business competitiveness performance represents the total e-business performance of a firm in a competitiveness perspective. It includes sale growth rate and customer share. Our findings present a comprehensive and structural tool that can efficiently measure EEBP in terms of a total e-business performance from e-business operation performance to e-business competitiveness performance, including 4 measurement factors and 11 items as shown in Fig. 1.

\begin{tabular}{|c|c|c|c|}
\hline \multicolumn{1}{|c|}{$\begin{array}{c}\text { Measurement Tool } \\
\text { for EEBP }\end{array}$} \\
\hline $\begin{array}{c}\text { E-business } \\
\text { Operation } \\
\text { Performance } \\
(\text { V01, V03, V04) }\end{array}$ & $\begin{array}{c}\text { E-business } \\
\text { Growth } \\
\text { Performance } \\
(\text { V06, V08, V10) }\end{array}$ & $\begin{array}{c}\text { E-business } \\
\text { Profitability } \\
\text { Performance } \\
(\text { V13, V15, V17) }\end{array}$ & $\begin{array}{c}\text { E-business } \\
\text { Competitiveness } \\
\text { Performance } \\
\text { (V19, V21) }\end{array}$ \\
\hline
\end{tabular}

E-business Operation Performance

-V01 : Efficiency of business process in e-business management activities

-V03 : Quality of service in e-business customer service department

-V04 : Client satisfaction in e-business customer contact department

E-business Growth Performance

-V06 : Return growth on sale in e-business sale revenue department

-V08: Sale revenue growth in e-business sale revenue department

-V10 : Market growth in domestic and oversea e-business market department

E-business Profitability Performance

-V13: Growth in profits in annual e-business profits outcome department

-V15 : Sale growth and profit margin in e-business sale revenue department

-V17 : Net income growth in annual e-business income department

E-business Competitiveness Performance

-V19: Sale growth rate in domestic and oversea e-business sale department

-V21: Customer share in domestic and oversea e-business customer market

Fig. 1. The developed tool framework with measurement factors and items. 
As shown in Table I and Fig. 1, e-business operation performance has the measurement items, such as V01, V03, and V04. E-business growth performance comprises V06, V08, and V10. E-business profitability performance contains $\mathrm{V} 13, \mathrm{~V} 15$, and V17. E-business competitiveness performance consists of V19 and V21. These factors affect EEBP, that is, the total EEBP of an enterprise. It is important to manage and improve EEBP by measuring an enterprise e-business performance with a valid and reliable instrument.

Therefore, understanding the EEBP construct is essential to measure the success of EEBP that denotes the total e-business performance to efficiently support its management activities. This research can use the comprehensive and structural tool to measure EEBP across different industrial fields and business departments, and perhaps even as a global measure. Hence, the developed tool is an important theoretical construct to efficiently gauge the total e-business performance that an enterprise can obtain by applying its e-business capability to its management activities in a global management environment.

Additionally, this research analyzed the mutual relationship between the analysis factors, and the relationship between each factor and EEBP. Since there are the factors affecting EEBP, understanding their mutual relationship is very important for efficiently improve EEBP and for the effective utilization of the developed tool in industrial fields. Their mutual relationship is complex and may be affected by other variables. This research analyzed how they were correlated in order to examine the relationship between e-business operation performance, e-business growth performance, e-business profitability performance, and e-business competitiveness performance, and EEBP, as shown in Table III.

TABLE III: CORRELATION MATRIX

\begin{tabular}{|c|c|c|c|c|c|}
\hline \multirow{2}{*}{ Division } & \multicolumn{5}{|c|}{ Factor Correlation Matrix } \\
\hline & & (2) & (3) & (4) & (5) \\
\hline EEBP & (1) & 0.44 & 0.49 & 0.43 & 0.41 \\
\hline $\begin{array}{l}\text { E-business Operation } \\
\text { Performance }\end{array}$ & (2) & & 0.44 & 0.45 & 0.43 \\
\hline $\begin{array}{l}\text { E-business Growth } \\
\text { Performance }\end{array}$ & (3) & & & 0.43 & 0.47 \\
\hline $\begin{array}{l}\text { E-business Profitability } \\
\text { Performance }\end{array}$ & (4) & & & & 0.42 \\
\hline $\begin{array}{l}\text { E-business Competitiveness } \\
\text { Performance }\end{array}$ & (5) & & & & \\
\hline
\end{tabular}

\section{CONCLUSION}

This study provides a comprehensive and structural tool that can measure perceived EEBP from a total e-business performance perspective. This 11-item scale is implicative, concrete, easy to use, and appropriate for practical and research purposes. This research also has some limitations in terms of a specific EEBP perspective. The developed tool with adequate validity and reliability provides groundwork for the development of a standard framework of EEBP.

Therefore, this study presents a comprehensive tool that can efficiently measure EEBP that an enterprise can obtain by applying a firm e-business capability to its management activities and business tasks in a global management environment. This result provides a new direction and foundation for the development and advancement of the efficient measurement tool for EEBP. In future research, we will find the practicality and availability of this measurement tool with providing the measurement results by applying it to a lot of case studies.

\section{APPENDIX}

1) Efficiency of business process in e-business management activities

2) Inventory turnover and accounts in e-business management activities

3) Quality of service in e-business customer service department

4) Client satisfaction in e-business customer contact department

5) Market value in domestic and oversea e-business market department

6) Return growth on sale in e-business sale revenue department

7) Return on sale in e-business sale revenue department

8) Sale revenue growth in e-business sale revenue department

9) Sale growth in total e-business sale department

10) Market growth in domestic and oversea e-business market department

11) Cash turnover ratio in e-business sale revenue department

12) Market share in domestic and oversea e-business customer market

13) Growth in profits in annual e-business profits outcome department

14) Capital structure in enterprise total e-business assets

15) Sale growth and profit margin in e-business sale revenue department

16) Number of patents related to e-business possessed by enterprise

17) Net income growth in annual e-business income department

18) $R \& D$ expenditure in total management expenditure the acknowledgment.

19) Sale growth rate in domestic and oversea e-business sale department

20) Sale growth in domestic and oversea e-business sale department

21) Customer share in domestic and oversea e-business customer market

\section{ACKNOWLEDGMENT}

This research was supported by Basic Science Research Program through the National Research Foundation of Korea (NRF) funded by the Ministry of Education, Science and Technology (NO: 2013R1A1A2012350).

\section{REFERENCES}

[1] C. Y. Yoon and C. S. Leem, "A Classification of e-Business Human Resources and Its Applications," Study of Internet and Electronic Commerce, vol. 6, no. 2, pp. 1-22, 2006.

[2] C. S. Leem and E.-B. Lab, e-Business File, Young-Jin Publications Co., 2003. 
[3] C. Y. Yoon, "A comprehensive instrument for measuring individual competency of IT applications in an enterprise IT environment," IEICE Trans on Information and Systems, vol. E95-D, no. 11, pp. 2651-2657, 2012.

[4] C. Y. Yoon, "A structural tool to efficiently analyze enterprise smart business capability in a total smart business capability perspective," iNFORMATION An International Interdisciplinary Journal, vol. 17, no. 11-A, pp. 5607-5618, 2014.

[5] X. Bi and H. Zhang, "An empirical research on relationship between information technology capability and firm performance: The evidence from listed companies and information power 500 in China," in Proc. International Conference on Computer Science and Software Engineering, 2008, pp. 540-544.

[6] B. Hu and Y. Xiang, "An empirical study of effects of information systems resources," in Proc. International Seminar on Future Information Technology and Management Engineering, 2008, pp. 335-338.

[7] S. J. Choi and I. S. Ko, "The influence of relationship specificity of invested assets on electronic collaboration and firm's performance in small and medium enterprises," The Journal of MIS Research, vol. 16 , no. 4, pp. 121-149, 2006.

[8] B. Hu and Y. Xiang, "An empirical study of effects of information systems resources," in Proc. International Seminar on Future Information Technology and Management Engineering, 2008, pp. 335-338.

[9] H. Jiao, C. Chang, and Y. Lu, "The relationship on information technology capability and performance: An empirical research in the context of China's Yangtze River Delta Region," in Proc. IEEE International Conference on Industrial Engineering and Engineering Management, 2008, pp. 872-876.

[10] C. Liao and S. H. Chuang, "Exploring the role of knowledge management for enhancing firm's innovation and performance," in Proc. the 39th Hawaii International Conference on System Sciences, 2006, vol. 7, pp. 158a-167a.

[11] Z. Q. Liu and Y. J. Feng, "An analysis of diversification and firm Performance," in Proc. the 15th International conference on Management Science \& Engineering, 2008, pp. 456-461.

[12] Y. Liu, T. Ravichandran, S. Han, and I. Hasan, "Complementarities between IT and firm diversification and performance implications," in Proc. the 39th Hawaii Conference on System Sciences, 2006, vol. 8, pp. $167 \mathrm{c}-176 \mathrm{c}$.

[13] J. Jiang and J. Zhang, "Strategic co-operative E \& D and firm performance in emerging $\mathrm{B} 2 \mathrm{~B}$ e-commerce," in Proc. the IEEE International Conference on e-Business Engineering, 2008, pp. 537-542.

[14] J. Sun, J. Ding, and X. Gu, "Empirical study on impact of information technology on construction firm performance," in Proc. International
Conference on Information Management, Innovation Management and Industrial Engineering, 2008, pp. 54-57.

[15] F. M. Tseng, Y. J. Chiu, and J. S. Chen, "Measuring business performance in the high-tech manufacturing industry: A case study of Taiwan's large-sized TFT-LCD panel companies," The International Journal of Management Science, vol. 37, pp. 686-697, 2009.

[16] S. Mei and M. Nie, "technology capability, marketing capability and network capability: Keys to enhancing competitiveness and improving performance," in Proc. the 14th International Conference on Management Science \& Engineering, 2007, pp. 728-733.

[17] M. J. Tippins and R. S. Sohi, "IT competency and firm performance: Is organizational learning a missing link," Strategic Management Journal, vol. 24, pp. 745-761, 2003

[18] J. Etezadi-Amoli and A. F. Farhoomand, "A structural model of end user information satisfaction and user performance," Information \& Management, vol. 30, pp. 65-73, 1996.

[19] G. Torkzadeh and J. W. Lee, "Measures of perceived end-user's information skills," Information \& Management, vol. 40, pp. 607-615, 2003 .

[20] A. M. Aladwani and P. C. Palvia, "Developing and validating an instrument for measuring user web quality," Information and Management, vol. 39, no. 6, pp. 467-476, 2002.

[21] D. T. Campbell and D. W. Fiske, "Convergent and discriminant validation by multitrait-multimethod matrix," Psychological Bulletin, vol. 56, no. 2, pp. 81-105, 1959.

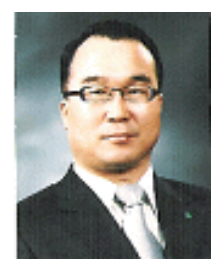

Chui Young Yoon received the $\mathrm{Ph} . \mathrm{D}$. degree in computer science \& industrial system engineering from Yonsei University, Seoul, South Korea in 2003. He worked as a professor at Seoul Cyber University for 2003-2005 and an associate professor at College of Electrical \& Computer Engineering in Chungbuk National University for 2006-2010, and is a professor at the Department of IT-Applied Convergence in Korea National University of Transportation, Chungju City, Chungbuk, South Korea. He has registered in Marquis Who's Who in the World/Science and Engineering (2009-2015), "Great Minds of the 21st Century" (2010-2013), ABI, and "Outstanding Intellectuals of the 21 st Century" (2010-2013), IBC. He has participated as a TPC member and a section chair of IEEE IEEM, ICMIT, CSCWD, ICCSIT international conferences. His research interests include information system, knowledge-based systems, and measurement of individual and enterprise IT competency, management engineering, human-computer interaction, and ubiquitous computing technology. 